\title{
Easy to swallow: detection of an extramural jejunal GIST by video capsule endoscopy
}

\author{
Ricky Kauser, ${ }^{1}$ Ali Kazemi, ${ }^{2}$ Katie Farah, ${ }^{2}$ Suzanne Morrissey ${ }^{2}$
}

'Department of Medicine, Allegheny Health Network, Allegheny General Hospital, Pittsburgh, Pennsylvania, USA ${ }^{2}$ Division of Gastroenterology, Allegheny Health Network, Allegheny General Hospital, Pittsburgh, Pennsylvania, USA

\section{Correspondence to}

Dr Ali Kazemi,

akazemi@wpahs.org

Accepted 25 September 2015

\section{SUMMARY}

We report a case of a 57-year-old woman with an obscure gastrointestinal bleed who was found to have an extramural gastrointestinal stromal tumour (GIST), detected by capsule endoscopy, and confirmed by laparoscopically-assisted enteroscopy and resection. Currently, major modalities used for detection of GISTS include double-balloon enteroscopy, capsule endoscopy and CT. Endoscopic measures, including capsule endoscopy, are limited in their ability to detect GISTs with extramural growth, as these typically do not demonstrate obvious luminal abnormalities. This case report illustrates a case in which an extraluminal GIST causing recurrent gastrointestinal bleeding presented as an ulcer, as seen on capsule endoscopy.

\section{BACKGROUND}

Small bowel tumours are a rare cause of gastrointestinal (GI) malignancies. ${ }^{1}$ GI stromal tumours (GISTs) are the most common mesenchymal tumours of the GI tract and typically present in the stomach, although up to $20-35 \%$ can present in the small bowel. ${ }^{2}$ Most GISTs are located intramurally, and thus present as luminal lesions. However, $20 \%$ are considered extramural and occur as exophytic masses protruding through the serosa. ${ }^{3}$ Our case illustrates obscure GI bleeding secondary to an extramural jejunal GIST detected by capsule endoscopy.

\section{CASE PRESENTATION}

A 57-year-old Caucasian woman with a 1 year history of obscure, overt bleeding, presented to our institution, with bright red blood per rectum. She initially presented to an outside hospital 1 year prior, with symptomatic anaemia.

\section{INVESTIGATIONS}

The patient underwent an oesophagogastroduodenoscopy (OGD) and colonoscopy as well as two capsule endoscopies at an outside community hospital, to investigate the source of bleeding. The OGD and colonoscopy were normal. The first capsule endoscopy study demonstrated a large, cratered ulcer in the mid small bowel. Several weeks later, repeat capsule endoscopy showed no evidence of the ulcer; this was attributed to healing of the ulcer.

The patient was asymptomatic for months until she again presented to our facility, with haematochezia. Repeat OGD and colonoscopy were negative. An antegrade single-balloon enteroscopy was normal, and a tattoo was placed endoscopically. A repeat capsule endoscopy showed an abnormal vascular lesion distal to the previously placed tattoo. This was followed by a retrograde single-balloon enteroscopy, which was normal, but did not reach the initial tattooed area. A spirus enteroscopy was performed and was passed distal to the tattooed site, but the abnormal vascular collection seen on capsule endoscopy was not visualised. During her most recent hospital admission, the patient presented with crampy, midepigastric pain and haematochezia. In the emergency department, she reported fatigue, light-headedness and dizziness. Physical examination of the abdomen showed a soft, non-tender, non-distended abdomen, with normal bowel sounds. Haemoglobin was $7.9 \mathrm{~g} / \mathrm{L}$ (normal range: $12-15 \mathrm{~g} / \mathrm{dL}$ in women, $13-17 \mathrm{~g} / \mathrm{dL}$ in men). In order to visualise the source of active bleeding, capsule endoscopy was pursued, showing a clean-based, umbilicated, submucosal lesion with ulceration in the mid small bowel (figure 1). The patient was taken to the operating room, where a laparoscopically-assisted enteroscopy was performed. There was difficulty passing the small bowel over the endoscope. Using manual palpation, the bowel was found to be tethered due to a large mass in the small bowel. The location and appearance of the mass correlated with that of the ulceration seen on the capsule endoscopy. A smallbowel resection with end-to-end anastomosis was performed. The exophytic mass measured $5.5 \times 5.5 \times 3.5 \mathrm{~cm}$ (figure 2). On the small bowel mucosa, at the area of attachment of the exophytic

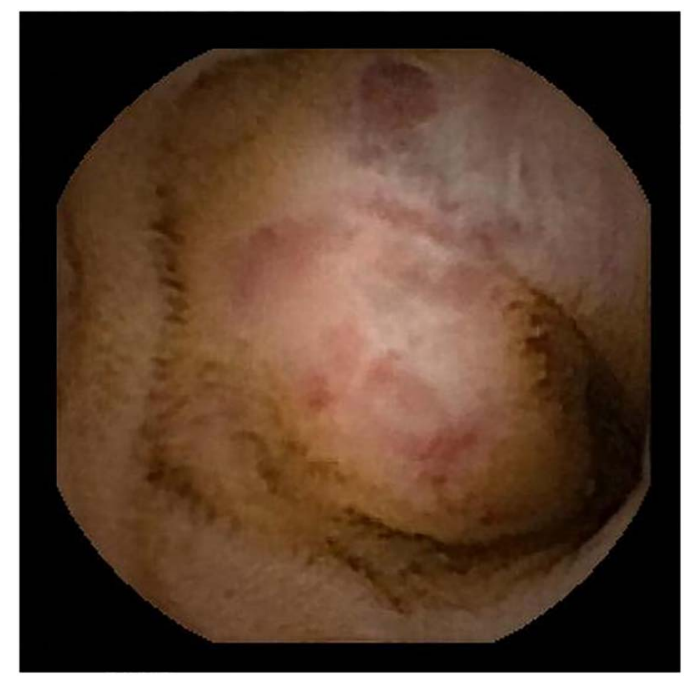

Figure 1 Image from capsule endoscopy revealing evidence of an ulcerated lesion atop a bulge suggestive of a submucosal lesion. 


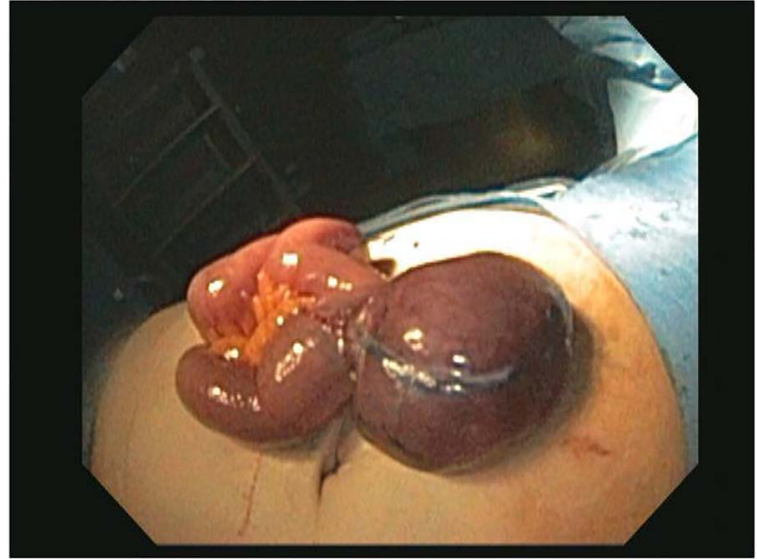

Figure 2 Exophytic mass emerging from a loop of small bowel noted during a laparoscopically-guided enteroscopy.

mass, was a $1.0 \times 0.6 \mathrm{~cm}$, ulcerated opening with haemorrhagic, raised edges. Pathology revealed a low-grade GIST of spindle cell subtype, with a mitotic rate of $3 / 50$ high power field. Margins were free of tumour, and tumour node metastasis (TNM) staging was pT3. By immunohistochemistry, the tumour cells were positive for CD 34 and CD 117.

\section{OUTCOME AND FOLLOW-UP}

After successful surgical resection, the patient did not have further active bleeding and was otherwise asymptomatic. She was discharged, and is to be evaluated by oncology for further management.

\section{DISCUSSION}

GISTs are the most common mesenchymal tumours of the GI tract. They are more common in men and African-Americans, and have a median age of diagnosis of 63 years. ${ }^{4}$ GISTs are most common in the stomach (60-70\%), followed by the small intestine (20-35\%), the colon and rectum (5\%), and, finally, the oesophagus $(<5 \%) .^{5}$

Nearly $75 \%$ of GISTs are composed of spindle cells, whereas the remaining consist of epithelioid cells. ${ }^{6}$ In over $90 \%$ of cases, a tyrosine kinase receptor protein (CD117) is expressed, which, along with histology, aids in diagnosis. ${ }^{7}$ The expression of CD117 also helps differentiate GISTs from other mesenchymal tumours of the GI tract, such as leiomyomas and leiomyosarcomas, and guides treatment selection. ${ }^{9}$ Approximately $4 \%$ of GISTs do not express CD117, and these tend to be composed of epithelioid cells, and arise from the peritoneum and omentum. ${ }^{8}$

The most common presentation of GISTs is a GI bleed, though patients may present with abdominal pain, early satiety, bloating, obstructive jaundice and dysphagia. ${ }^{5} 10$ GISTs are often detected incidentally by a CT of the abdomen obtained during the evaluation of these symptoms. Nonetheless, they may also be suspected in cases where there is a subepithelial mass on endoscopy.

Multiple studies are commonly used to investigate small bowel tumours including enteroclysis, MRI, angiography, capsule endoscopy, double balloon enteroscopy (DBE) and CT. Nakatani et $a l,{ }^{2}$ in a retrospective study, concluded that DBE is useful in detecting GISTs in the small bowel; however, a combination of capsule endoscopy and CT may also be useful. Lesions such as submucosal tumours may be detected more readily by capsule endoscopy due to luminal impingement and overlying ulceration. In the same study, intramural GISTs tended to present as round, ulcerated lesions on endoscopy. ${ }^{2}$ In a study by Pennazio et al, ${ }^{11} 100$ consecutive patients with overt GI bleeding were examined with capsule endoscopy. The results indicated that capsule endoscopy can reach a positive predictive value of $97 \%$ if used early in a patient who is actively bleeding. In regard to the usage of spiral enteroscopy versus DBE, Freiling et $a l^{12}$ demonstrated that DBE actually may have a higher diagnostic yield as compared to spiral enteroscopy. However, in our institution since only single balloon and spiral enteroscopy are available, these methods were used to further evaluate the source of bleeding in this patient.

Capsule endoscopy is limited in its ability to detect GISTs with extramural growth unless there is extension to the lumen. Some extramural duodenal GISTs have been shown to mimic a pancreatic head mass on CT, but did not show any mucosal abnormality on endoscopy. ${ }^{13}$ Extramural growth of GISTs has been reported in 18-30\% of GISTs. ${ }^{3}$ The combination of modalities is especially useful in detecting extramural GISTs. ${ }^{2}$ These often present as well delineated, heterogeneous and, occasionally, exophytic masses, on CT. ${ }^{14}$ Although CT is extremely useful in detecting large tumours and GISTs with extramural growth, the detection rate of intramural GISTs was low. $^{2}$ In our case, a CT of the abdomen with contrast had been performed on a previous hospital visit a few months prior to the diagnosis of the GIST. Unfortunately, the lesion was not reportedly seen due to the difficulty in differentiating it from the other loops of small bowel, which led to the significant endoscopic work up that ensued.

Surgical resection is the standard therapy for non-metastatic GISTs. ${ }^{15}$ According to the National Comprehensive Cancer Network, all GISTs $\geq 2 \mathrm{~cm}$ should be resected as there is greater malignant potential. Tumour size and mitotic activity strongly influence the clinical outcome. ${ }^{2}$ One study found that $<3 \%$ intestinal GISTs that were $<5 \mathrm{~cm}$ and $\leq 5$ mitoses per $50 \mathrm{HPF}$ metastasised; whereas, $86 \%$ of tumours $>10 \mathrm{~cm}$ and $>5$ mitoses per $50 \mathrm{HPF}$ metastasised. ${ }^{2}$ Therefore, an accurate diagnosis is paramount to adequately triage these patients and discern the appropriate treatment plan. This includes detailed history-taking and physical examination to properly understand associated signs and symptoms, followed by imaging and endoscopic evaluation including but not limited to an OGD, anterograde or retrograde deep enteroscopy, or capsule endoscopy, until these lesions are fully characterised and localised.

\section{Learning points}

- Identification of GISTs is important as they frequently metastasise and their malignant potential depends greatly on size, location and rate of mitosis.

- Extramural GISTs are less likely than intramural lesions to present with mucosal irregularities, therefore they may be difficult to detect with a single modality.

- Submucosal tumours may be detected more readily by capsule endoscopy due to luminal impingement and overlying ulceration.

- Capsule endoscopy is limited in its ability to detect GISTs with extramural growth unless there is extension to the lumen.

- Our case illustrates that extramural mass lesions may present as mucosal ulcerations on video capsule endoscopy. 
Competing interests None declared.

\section{Patient consent Obtained.}

Provenance and peer review Not commissioned; externally peer reviewed.

\section{REFERENCES}

1 Neugut Al, Jacobson JS, Suh S, et al. The epidemiology of cancer of the small bowel. Cancer Epidemiol Biomarkers Prev 1998;7:243-51.

2 Nakatani M, Fujiwara Y, Nagami Y, et al. The usefulness of double-balloon enteroscopy in gastrointestinal stromal tumors of the small bowel with obscure gastrointestinal bleeding. Intern Med 2012;51:2675-82.

3 Giglio L, Andreoli G. GIST: evaluation by spiral CT and angiography. Eur J Radiol 2001;3:250-61.

4 Tran T, Davila JA, El-Serag HB. The epidemiology of malignant gastrointestinal stromal tumors: an analysis of 1458 cases from 1992 to 2000. Am J Gastroenterol 2005:100:162-8.

5 Miettinen M, Sobin LH, Lasota J. Gastrointestinal stromal tumors of the stomach: a clinicopathologic, immunohistochemical, and molecular genetic study of 1765 cases with long-term follow-up. Am J Surg Pathol 2005;29:52-68.

6 Miettinen M, Sarlomo-Rikala M, Lasota J. Gastrointestinal stromal tumors: recent advances in understanding of their biology. Hum Pathol 1999;30:1213-20.
7 Desai DJ, Kamath MD, Haldar PJ. Jejunal GIST with extramural hemangiomatous component presenting as an obscure lower GI bleed: a case report. Indian J Surg 2008;70:37-9.

8 Medeiros F, Corless CL, Duensing A, et al. KIT-negative gastrointestinal stromal tumors: proof of concept and therapeutic implications. Am J Surg Pathol 2004;28:889-94.

9 Rubin BP, Fletcher JA, Fletcher CD. Molecular insights into the histogenesis and pathogenesis of gastrointestinal stromal tumors. Int I Surg Pathol 2000:8:5-10.

10 Ohmiya N, Yano T, Yamamoto $\mathrm{H}$, et al. Diagnosis and treatment of obscure $\mathrm{Gl}$ bleeding at double balloon endoscopy. Gastrointest Endosc 2007;66:S72-7.

11 Pennazio M, Santucci R, Rondonotti E, et al. Outcome of patients with obscure gastrointestinal bleeding after capsule endoscopy: Report of 100 consecutive cases. Gastroenterology 2004;3:643-53.

12 Freiling T, Heise J, Sassenrath W, et al. Prospective comparison between double-balloon enteroscopy and spiral enteroscopy. Endoscopy 2010;42:885-8.

13 Hiroki U, Atsushi S, Iwaki K, et al. An extramural gastrointestinal stromal tumor of the duodenum mimicking a pancreatic head tumor. J Hepatobiliary Pancreat Surg 2005; 12:324-7

14 Bensimhon $\mathrm{D}$, Soyer $\mathrm{P}$, Boudiaf $\mathrm{M}$, et al. Imaging of gastrointestinal stromal tumors. J Radiol 2009;90:469-80.

15 Joensuu H. Gastrointestinal stromal tumor (GIST). Ann of Oncol 2006;17(Suppl 10): x280-6.

Copyright 2015 BMJ Publishing Group. All rights reserved. For permission to reuse any of this content visit http://group.bmj.com/group/rights-licensing/permissions.

BMJ Case Report Fellows may re-use this article for personal use and teaching without any further permission.

Become a Fellow of BMJ Case Reports today and you can

- Submit as many cases as you like

- Enjoy fast sympathetic peer review and rapid publication of accepted articles

- Access all the published articles

- Re-use any of the published material for personal use and teaching without further permission

For information on Institutional Fellowships contact consortiasales@bmjgroup.com

Visit casereports.bmj.com for more articles like this and to become a Fellow 